\title{
Genome Sizes and Ploidy Levels in the Genus Kalmia
}

\author{
Dominic A. Gillooly ${ }^{1}$ and Thomas G. Ranney ${ }^{2,3}$ \\ Mountain Crop Improvement Lab, Department of Horticultural Science, \\ Mountain Horticultural Crops Research and Extension Center, North \\ Carolina State University, 455 Research Drive, Mills River, NC 28759
}

Additional index words. cytology, DNA content, flow cytometry, Kalmia angustifolia, K. buxifolia, K. carolina, K. cuneata, K. hirsuta, K. latifolia, K. microphylla, K. polifolia, polyploidy, plant breeding

\begin{abstract}
Kalmia is a highly ornamental genus of shrubs native to North America and Cuba and grown as a valuable nursery crop throughout much of the temperate world. Although most species of Kalmia have previously been found to be diploid with $\mathbf{2 n}=\mathbf{2 x}=\mathbf{2 4}$, one species, Kalmia polifolia, has been found to be tetraploid. However, sampling within the genus has been limited, and information on the ploidy levels of specific cultivars is lacking. The objective of this study was to determine the relative genome sizes and ploidy levels of species, hybrids, and cultivars of Kalmia. Flow cytometry was used to determine the relative genome sizes of 67 accessions representing species, interspecific hybrids, cultivars, and chemically induced polyploids. Traditional cytology was used to calibrate genome sizes with ploidy levels. Results showed that relative genome sizes were conserved with $1 \mathrm{Cx}$ values ranging from $0.57 \mathrm{pg}$ for Kalmia carolina to $0.70 \mathrm{pg}$ for Kalmia latifolia. Most species of Kalmia were diploid including K. buxifolia (Leiophyllum buxifolium), K. carolina, K. cuneata, K. hirsuta, K. latifolia, and $K$. microphylla. Although plants of $K$. carolina (Kalmia angustifolia var. carolina) were uniformly diploid, the closely related, but more northerly distributed, $K$. angustifolia was primarily tetraploid, providing additional justification for treating these as separate species. An unusual triploid of $K$. angustifolia $f$. candida was also documented. Kalmia polifolia included both tetraploid and potentially pentaploid individuals, indicating a ploidy series within this species. Kalmia latifolia cultivars also included one triploid, two cytochimeras, and two chemically induced tetraploids. Overall, polyploidy was more prevalent in Kalmia than previously reported and varied both within and among species. This broader survey of relative genome sizes and ploidy levels in Kalmia provides valuable information for plant breeders and new insights into the systematics and cytogenetics of the genus.
\end{abstract}

Kalmia L. is a small but diverse genus containing nine to 11 species (Ebinger, 1974; Southall, 1973; Weakley, 2012) native to North America and Cuba (Jaynes, 1997).

Received for publication 8 June 2015. Accepted for publication 20 Aug. 2015

This research was funded, in part, by the North Carolina Agricultural Research Service, Raleigh, $\mathrm{NC}$, and the North Carolina Biotechnology Center, Research Triangle Park, NC.

Technical assistance of Nathan Lynch, Joel Mowrey, Tom Eaker, and Jeremy Smith is gratefully acknowledged. We also thank Kelly Brooks, Southern Highlands Reserve, Lake Toxaway, NC; Geordie Elkins, Highstead, Redding, CT; Eric La Fountaine, University of British Columbia Botanical Garden and Center for Plant Research, Vancouver, BC; Dr. Richard Jaynes, Broken Arrow Nursery, Hamden, CT; Bambi Jones, Hidden Valley Nature Center, Jefferson, ME; Dr. Ron Miller, Pensacola, FL; Cliff Ruth, North Carolina Cooperative Extension Service, Asheville, NC; and Dr. Elizabeth Thompson, University of Vermont, Burlington, VT, for their help in locating and procuring the samples used in this study.

${ }^{1}$ Graduate Research Assistant.

${ }^{2}$ Professor.

${ }^{3}$ Corresponding author. E-mail: tom_ranney@ncsu. edu.
Deciduous or evergreen woody shrubs, Kalmia spp. have a varied morphology and are each distinct. Some of their diverse characteristics include plants that are "... erect, or ascending, branching shrubs or rarely trees. The leaves are simple, alternate, opposite or whorled, coriaceous, dark green above, light green beneath, entire and often revolute (Southall, 1973)." Kalmia latifolia, and to a lesser degree, $K$. angustifolia L. and $K$. polifolia Wangenh. are valuable nursery crops and have been cultivated in North America and Europe since the early 1700s (Jaynes, 1997).

Cytology was performed on Kalmia species by Dr. Richard Jaynes of the Connecticut Agricultural Experiment Station in the late 1960s (Jaynes, 1969). His examinations found most species of Kalmia to be diploid $(2 n=2 x=24)$, with the exception of $K$. polifolia that was tetraploid $(2 n=4 x=48)$. However, that study only examined material from one or two plants per species to determine ploidy, and in the case of $K$. angustifolia, only samples from North Carolina were obtained as representatives of that species (Jaynes, 1969). Kalmia angustifolia and $K$. carolina Small [K. angustifolia var. carolina (Small) Fernald] are closely related with North Carolina provenances now generally classified as K. carolina (Gillespie and Kron, 2010; Southall and Hardin, 1974; Weakley, 2012). Cytology on Ericaceous plants, including Kalmia, is notoriously difficult, due in part to the small chromosomes (Jaynes, 1997). Flow cytometry provides a more efficient approach to broaden sampling within and among species and can provide accurate estimates of ploidy, particularly for Ericaceous plants (Jones et al., 2007).

The objective of this study was to survey genome sizes and ploidy levels of a broad range of species, hybrids, and cultivars of Kalmia from throughout North America.

\section{Materials and Methods}

A diverse collection of Kalmia taxa was obtained from cooperators in the United States and Canada (Table 1). The Cuban species Kalmia ericoides C. Wright ex Griseb. was not available for analysis. Relative $2 \mathrm{C}$ genome sizes were determined using flow cytometry on recently expanded leaves (Greilhuber et al., 2007). Sample tissue was combined with an internal standard (Pisum sativum L. 'Ctirad', 2C DNA content $=8.76$ pg, Greilhuber et al., 2007) and diced with a razor blade in a petri dish containing $400 \mu \mathrm{L}$ of extraction buffer (CyStain Precise P; Partec, Münster, Germany). The nuclei suspension was poured through a $50-\mu \mathrm{m}$ filter and stained with $1600 \mu \mathrm{L}$ of a nucleotide staining buffer solution (CyStain ultraviolet Precise P Staining Buffer, Partec) containing 4', 6-diamidino-2-phenylindole. Stained nuclei were analyzed using the PA-II flow cytometer (PA-II; Partec). A minimum of 3000 nuclei counts were analyzed for each sample with three samples for each species. Holoploid, 2C genome sizes for each sample were calculated as: $2 \mathrm{C}=\mathrm{DNA}$ content of standard $\times$ (mean fluorescence value of sample $\div$ mean fluorescence value of the standard). The relationship between genome sizes and ploidy levels was based on samples with confirmed chromosome numbers. Mean $1 \mathrm{Cx}$ monoploid genome size (i.e., genome size of the nonreplicated base set of chromosomes) was calculated as $2 \mathrm{C}$ genome size $\div$ ploidy. Taxa were sampled in a completely randomized fashion. Data for $1 \mathrm{Cx}$ values were subjected to analysis of variance and means. Different taxa were separated using Tukey's honestly significant difference, $P \leq 0.05$ (SAS version 8.02; SAS Institute, Cary, NC).

Cytology. To confirm ploidy and calibrate with genome size the cultivar $K$. latifolia 'Elf' was selected and traditional cytology was conducted using a root squash technique following procedures outlined in Lattier et al. (2014). Root tips were collected from potted plants and placed in vials of prefixative solution (2 mm 8-hydroxyquinoline $+70 \mathrm{mg} \cdot \mathrm{L}^{-1}$ cycloheximide). Vials were stored in the dark for $2 \mathrm{~h}$ at ambient room temperature after which they were placed in a dark refrigerator at $\approx 4{ }^{\circ} \mathrm{C}$ for an additional $2 \mathrm{~h}$. Following the prefixative period, roots were removed and rinsed thoroughly in deionized water. The 
Table 1. Relative genome sizes and estimated ploidy levels for 67 accessions of Kalmia species, cultivars, and hybrids.

\begin{tabular}{|c|c|c|c|c|}
\hline Taxa/cultivar & Source/accession no. & $\begin{array}{c}\text { Relative } 2 \mathrm{C} \\
\text { genome size }(\mathrm{pg})\end{array}$ & $\begin{array}{c}\text { Est. ploidy } \\
\text { level }(x)\end{array}$ & $\begin{array}{c}\text { Mean relative } 1 \mathrm{C} \text { genome } \\
\text { size }(\mathrm{pg}) \text { by taxa }\end{array}$ \\
\hline Kalmia angustifolia 'Royal Dwarf' & NCSU 2003-131 z & $2.36 \pm 0.02^{\mathrm{y}}$ & 4 & $0.58 \pm 0.00 \mathrm{DE}^{\mathrm{x}}$ \\
\hline Kalmia angustifolia 'Hammonasett' & Highstead & $2.31 \pm 0.01$ & 4 & \\
\hline Kalmia angustifolia 'Royal Dwarf' & Highstead & $2.35 \pm 0.00$ & 4 & \\
\hline Kalmia angustifolia 'Poke Logan' & Highstead & $2.32 \pm 0.01$ & 4 & \\
\hline Kalmia angustifolia 'Wintergreen' & Highstead & $2.38 \pm 0.02$ & 4 & \\
\hline Kalmia angustifolia f. candida & Highstead & $1.74 \pm 0.00$ & 3 & \\
\hline Kalmia buxifolia & Southern Highlands 1 & $1.21 \pm 0.02$ & 2 & $0.60 \pm 0.00 \mathrm{DE}$ \\
\hline Kalmia buxifolia & Southern Highlands 2 & $1.20 \pm 0.04$ & 2 & \\
\hline Kalmia buxifolia & Southern Highlands 3 & $1.21 \pm 0.01$ & 2 & \\
\hline Kalmia carolina & NCSU 2003-110 & $1.17 \pm 0.06$ & 2 & $0.57 \pm 0.01 \mathrm{E}$ \\
\hline Kalmia carolina & NCSU 2012-126 & $1.15 \pm 0.02$ & 2 & \\
\hline Kalmia carolina & BRCC 1 & $1.12 \pm 0.00$ & 2 & \\
\hline Kalmia carolina & BRCC 2 & $1.10 \pm 0.00$ & 2 & \\
\hline Kalmia carolina & $\mathrm{BRCC} 3$ & $1.12 \pm 0.00$ & 2 & \\
\hline Kalmia hirsuta & Miller/NCSU 2013-068 & $1.35 \pm 0.00$ & 2 & $0.67 \pm 0.01 \mathrm{ABC}$ \\
\hline Kalmia hirsuta & Miller/NCSU 2013-069 & $1.32 \pm 0.01$ & 2 & \\
\hline Kalmia hirsuta & Miller/NCSU 2013-070 & $1.33 \pm 0.02$ & 2 & \\
\hline Kalmia latifolia 'Richard Jaynes' & NCSU 2004-074 & $1.34 \pm 0.02$ & 2 & $0.70 \pm 0.00 \mathrm{~A}$ \\
\hline Kalmia latifolia 'Hearts Desire' & NCSU 2011-011 & $1.39 \pm 0.01$ & 2 & \\
\hline Kalmia latifolia 'Kaleidoscope' & NCSU 2011-153 & $1.38 \pm 0.02$ & 2 & \\
\hline Kalmia latifolia 'Elf' & NCSU 2011-154 & $1.35 \pm 0.10$ & 2 & \\
\hline Kalmia latifolia 'Olympic Fire' & NCSU 2011-156 & $1.38 \pm 0.02$ & 2 & \\
\hline Kalmia latifolia 'Tinkerbelle' & NCSU 2011-157 & $1.37 \pm 0.05$ & 2 & \\
\hline Kalmia latifolia 'Minuet' & NCSU 2011-158 & $1.39 \pm 0.01$ & 2 & \\
\hline Kalmia latifolia 'Sarah' & NCSU 2011-159 & $1.36 \pm 0.04$ & 2 & \\
\hline Kalmia latifolia 'Fire Cracker' & NCSU 2011-160 & $1.41 \pm 0.03$ & 2 & \\
\hline Kalmia latifolia 'Little Linda' & NCSU 2011-161 & $1.42 \pm 0.01$ & 2 & \\
\hline Kalmia latifolia 'Tiddlywinks' & NCSU 2011-162 & $1.38 \pm 0.00$ & 2 & \\
\hline Kalmia latifolia 'Tidewater' & NCSU 2013-053 & $1.37 \pm 0.01$ & 2 & \\
\hline Kalmia latifolia & NCSU H2012-231-008 & $1.39 \pm 0.03$ & 2 & \\
\hline Kalmia latifolia & NCSU H2012-231-009 & $1.37 \pm 0.02$ & 2 & \\
\hline Kalmia latifolia 'Waxy Max' & Jaynes & $1.39 \pm 0.00$ & 2 & \\
\hline Kalmia latifolia & Jaynes pk-74 & $1.37 \pm 0.01$ & 2 & \\
\hline Kalmia latifolia 'Big Red' & Jaynes & $1.42 \pm 0.00$ & 2 & \\
\hline Kalmia latifolia 'Emerald Sheen' & Jaynes & $1.40 \pm 0.01$ & 2 & \\
\hline Kalmia latifolia & Jaynes 2-06-1 & $1.40 \pm 0.01$ & 2 & \\
\hline Kalmia latifolia & Jaynes 2-06-2 & $1.45 \pm 0.01$ & 2 & \\
\hline Kalmia latifolia & Jaynes 2-06-3 & $1.42 \pm 0.01$ & 2 & \\
\hline Kalmia latifolia & Jaynes 2-06-4 & $1.42 \pm 0.01$ & 2 & \\
\hline Kalmia latifolia & Jaynes 2-06-5 & $1.43 \pm 0.01$ & 2 & \\
\hline Kalmia latifolia & Jaynes 2-06-6 & $1.49 \pm 0.03$ & 2 & \\
\hline Kalmia latifolia & Jaynes 2-06-7 & $1.48 \pm 0.01$ & 2 & \\
\hline Kalmia latifolia & Jaynes 2-06-8 & $1.45 \pm 0.01$ & 2 & \\
\hline Kalmia latifolia & Jaynes 2-06-9 & $1.44 \pm 0.01$ & 2 & \\
\hline Kalmia latifolia & Jaynes 2-06-10 & $1.41 \pm 0.01$ & 2 & \\
\hline Kalmia latifolia & Jaynes 2-06-11 & $1.46 \pm 0.01$ & 2 & \\
\hline Kalmia latifolia & Jaynes 2-06-12 & $1.47 \pm 0.02$ & 2 & \\
\hline Kalmia latifolia & Jaynes 2-06-13 & $1.48 \pm 0.04$ & 2 & \\
\hline Kalmia latifolia 'Big Boy' & Woodlanders & $2.10 \pm 0.00$ & 3 & \\
\hline \multirow[t]{2}{*}{ Kalmia latifolia 'Showtime'w } & Jaynes & $1.40 \pm 0.00$ & 2 & \\
\hline & & $2.75 \pm 0.00$ & 4 & \\
\hline \multirow[t]{2}{*}{ Kalmia latifolia 'Silver Dollar'w } & Jaynes & $2.09 \pm 0.00$ & 3 & \\
\hline & & $4.21 \pm 0.03$ & 6 & \\
\hline Kalmia latifolia & NCSU H2014-222-002 & $2.77 \pm 0.00$ & 4 & \\
\hline Kalmia latifolia & NCSU H2014-222-004 & $2.74 \pm 0.00$ & 4 & \\
\hline$(K$. latifolia $\times K$. hirsuta $) \times K$. latifolia & Jaynes 1 & $1.40 \pm 0.01$ & 2 & $0.70 \pm 0.01 \mathrm{AB}$ \\
\hline$(K$. latifolia $\times K$. hirsuta $) \times K$. latifolia & Jaynes 2 & $1.41 \pm 0.00$ & 2 & \\
\hline$(K$. latifolia $\times K$. hirsuta $) \times K$. latifolia & Jaynes 3 & $1.38 \pm 0.01$ & 2 & \\
\hline Kalmia microphylla var. microphylla & UBC 1 & $1.37 \pm 0.03$ & 2 & $0.69 \pm 0.01 \mathrm{AB}$ \\
\hline Kalmia microphylla var. microphylla & UBC 2 & $1.36 \pm 0.03$ & 2 & \\
\hline Kalmia microphylla var. microphylla & UBC DM/2012-008PT 41559 & $1.41 \pm 0.02$ & 2 & \\
\hline Kalmia polifolia & HVNC & $2.59 \pm 0.01$ & 4 & $0.65 \pm 0.01 \mathrm{BC}$ \\
\hline Kalmia polifolia & Thompson 1 & $3.32 \pm 0.03$ & $\approx 5$ & \\
\hline Kalmia polifolia & Thompson 2 & $3.23 \pm 0.02$ & $\approx 5$ & \\
\hline Kalmia polifolia & Thompson 3 & $3.34 \pm 0.00$ & $\approx 5$ & \\
\hline Kalmia polifolia $\times$ microphylla var. microphylla 'Rocky Top' & Highstead & $2.37 \pm 0.00$ & 4 & $0.59 \pm 0.00 \mathrm{DE}$ \\
\hline
\end{tabular}

${ }^{\mathrm{z} B R C C}=$ Blue Ridge Community College, Flat Rock, NC; Highstead = Highstead Arboretum, Redding, CT; HVNC = Hidden Valley Nature Center, Jefferson, ME; Jaynes = Richard Jaynes, Broken Arrow Nursery, Hamden, CT; Miller = Ron Miller, Pensacola, FL; NCSU = North Carolina State University, Mountain Crop Improvement Laboratory, Mills River, NC; Southern Highlands = Southern Highlands Reserve, Lake Toxaway, NC; Thompson = Elizabeth Thompson, University of Vermont, Burlington, VT; UBC = University of British Columbia, Vancouver, BC, Canada; Woodlanders = Woodlanders Nursery, Aiken, SC.

yalues are means $(n=2) \pm$ SE.

${ }^{\mathrm{x}}$ Means followed by a common letter are not significantly different, Tukey's honestly significant difference, $P \leq 0.05$.

${ }^{\mathrm{w}}$ Mixoploid/cytochimera. 
rinsed root tips were then placed in a $3: 1$ solution of ethanol and propionic acid and left overnight at ambient room temperature to complete the fixation process. The following day, the roots were rinsed with $70 \%$ ethanol three times and stored in $70 \%$ ethanol at $\approx 4{ }^{\circ} \mathrm{C}$ until root squashes could be performed. Root tips were removed from the ethanol storage solution and placed in a hydrolyzing solution made up of a $3: 1$ solution of $95 \%$ ethanol and hydrochloric acid $(12.3 \mathrm{M})$ for $10 \mathrm{~min}$. After hydrolyzing, the root tips were transferred into a modified carbol-fuchsin staining solution for $10 \mathrm{~min}$. Once stained the terminal end of the root tip was excised under a dissecting stereo microscope and placed on a clean microscope slide in a drop of staining solution. A cover slip was applied, and the root tip tissue was squashed. Slides were observed using a light microscope (Nikon Eclipse 80i; Nikon, Melville, NY). Photographs, taken at multiple focal points, were layered (Photoshop CS6; Adobe, Mountain View, CA) to create an enhanced depth of field.

\section{Results and Discussion}

Cytology confirmed that $K$. latifolia 'Elf' is a diploid with $2 n=2 x=24$ (Fig. 1) as has been reported previously for that species (Jaynes, 1969). Flow cytometry was also an efficient and consistent method for determining relative genome size and ploidy of Kalmia (Table 1). Values for multiple subsamples of each replicate were consistent with $\mathrm{SE}$ for $2 \mathrm{C}$ values ranging from less than 0.01 to $0.1 \mathrm{pg}$ demonstrating a high level of precision and repeatability and clearly distinguishing between ploidy levels. Results from flow cytometry revealed that genome sizes were relatively conserved with $1 \mathrm{Cx}$ values ranging from $0.57 \mathrm{pg}$ for $K$. carolina to $0.70 \mathrm{pg}$ for $K$. latifolia. These values are similar to other Ericaceous plants, including Rhododendron that had $1 \mathrm{Cx}$ values ranging from 0.63 to $0.83 \mathrm{pg}$ (Jones et al., 2007). Cytometry results also showed there to be considerable variation in ploidy both between and within species (Table 1). Most species of Kalmia were predominantly diploid including $K$. buxifolia, $K$. carolina, $K$. cuneata, $K$. hirsuta, K. latifolia, and K. microphylla. In the case of $K$. latifolia, there were some exceptions. The cultivar K. latifolia Big Boy was a triploid, most likely the result of an unreduced gamete from one parent. There were also two mixoploid/cytochimeras found:

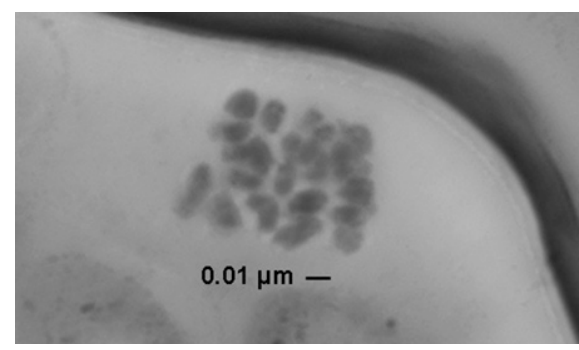

Fig. 1. Condensed chromosomes of Kalmia latifolia 'Elf' viewed at $1000 \times$ using oil immersion.
K. latifolia 'Showtime' had both diploid and tetraploid tissues, whereas 'Silver Dollar' had a mixture of triploid and hexaploid tissues. These mixoploids most likely arose from mitotic irregularities (endoreduplication) in at least one of the histogenic layers resulting in stable cytochimeras (Joubès and Chevalier, 2000). Naturally occurring mixoploids have been documented in other Ericaceous plants including Rhododendron (De Schepper et al., 2001; Jones et al., 2007; Sakai et al., 2006). In the case of 'Silver Dollar', this apparently happened in a triploid plant that most likely resulted from the union of an unreduced gamete from one of the parents. Two additional plants of $K$. latifolia, H2014-222-002 and H2014-222-004, were confirmed to be homogeneous tetraploids that resulted from treatment of seedlings with the mitotic inhibitor oryzalin at North Carolina State University.

As previously reported by Jaynes (1969), under the epitaph $K$. angustifolia var. carolina, the southern sheep laurel, $K$. carolina was confirmed to be diploid. However, samples of $K$. angustifolia, the northern sheep laurel, were all tetraploid, including 'Hammonasett', 'Poke Logan', 'Royal Dwarf', and 'Wintergreen'. The cultivars Hammonasett and Poke Logan are known to be wild collected selections from Connecticut and Maine, respectively (Jaynes, 1997). In addition, a sample of $K$. angustifolia f. candida, a white-flowered form, was triploid. Most likely this particular plant is an oddity and not necessarily representative of the white-flowered form in general.

Kalmia polifolia also varied in ploidy. A sample of $K$. polifolia obtained from Hidden Valley Nature Center in Jefferson, ME, was tetraploid. However, wild collected samples from Alburg, VT, had genome sizes consistent with pentaploids, though this could not be confirmed with cytology. The existence of putative pentaploid $K$. polifolia in the wild implies that there is a natural occurring ploidy series within the species, potentially including tetraploid, pentaploid and hexaploid individuals or populations. Additional sampling in this location would be warranted. Kron and King (1996) postulated that $K$. polifolia may be a hybrid between two lineages of Kalmia ancestors, which are no longer extant. It has often been found that interspecific hybrids have a greater propensity to form unreduced gametes leading to the formation of allopolyploids (Arnold, 2006; Ramsey and Schemske, 1998) and this may be the case for $K$. polifolia. The sample of the hybrid $(K$. polifolia $\times K$. microphylla var. microphylla) 'Rocky Top' was a tetraploid $(2 \mathrm{C}=2.37 \mathrm{pg})$, suggesting that it formed from the union of an unreduced gamete from the K. microphylla parent.

This survey provides new information on the genome sizes and ploidy levels for species, cultivars, and hybrids of Kalmia. The discovery and confirmation of new natural and induced polyploids within the genus provides basic information for how to best use these plants in breeding programs. Although development of interspecific hybrids in Kalmia has been challenging (Jaynes, 1997), attempting these crosses at the tetraploid level may result in allopolyploids (amphidiploids) with greater fertility because of disomic chromosome pairing in meiosis (Ranney, 2006), allowing for advanced generations. Alternatively, the development of new triploid hybrids of $K$. angustifolia and $K$. carolina has the potential to help reduce fertility and invasiveness where they have become problematic in European forests (Inderjit and Mallik, 1996).

\section{Literature Cited}

Arnold, M.L. 2006. Evolution through genetic exchange Oxford Univ. Press, Oxford.

De Schepper, S., L. Leus, M. Mertens, E. Van Bockstaele, and M. De Loose. 2001. Flow cytometric analysis of ploidy in Rhododendron (subgenus Tsutsusi). HortScience 36:125-127.

Ebinger, J.E. 1974. A systematic study of the genus Kalmia (Ericaceae). Rhodora 76:315-398.

Gillespie, E. and K. Kron. 2010. Molecular phylogenetic relationships and a revised classification of the subfamily Ericoideae (Ericaceae). Mol. Phylogenet. Evol. 56(1):343-354.

Greilhuber, J., E.M. Temsch, and J.C.M. Loureiro. 2007. Nuclear DNA content measurement, p. 67-101. In: J. Doležel, J. Greilhuber, and J. Suda (eds.). Flow cytometry with plant cells: Analysis of genes, chromosomes, and genomes. Wiley-VCH, Weinheim, Germany.

Inderjit, I. and A.U. Mallik. 1996. The nature of interference potential of Kalmia angustifolia. Can. J. For. Res. 26(11):1899-1904.

Jaynes, R.A. 1969. Chromosome counts of Kalmia species and revaluation $K$. polifolia var. microphylla. Rhodora 71:280-284.

Jaynes, R.A. 1997. Kalmia: Mountain laurel and related species. 3rd edTimber Press. Portland, OR.

Jones, J., T.G. Ranney, N.P. Lynch, and S.L. Krebs. 2007. Ploidy levels and relative genome sizes of diverse species, hybrids, and cultivars of rhododendron. J. Amer. Rhododendron Soc. 61 (4):220-227.

Joubès, J. and C. Chevalier. 2000. Endoreduplication in higher plants. Plant Mol. Biol. 43:735745.

Kron, K.A. and J.A. King. 1996. Cladistic relationships of Kalmia, Leiophyllum, and Loiseleuria (Phyllodoceae, Ericaceae) based on rbcL and nrITS data. Syst. Bot. 21(1):17-29.

Lattier, J.D., T.G. Ranney, P.R. Fantz, and T. Avent. 2014. Identification, nomenclature, genome sizes, and ploidy levels of Liriope and Ophiopogon taxa. HortScience 49:145-151.

Ramsey, J. and D.W. Schemske. 1998. Pathways, mechanisms and rates of polyploid formation in flowering plants. Annu. Rev. Ecol. Evol. Syst. 29:467-501.

Ranney, T.G. 2006. Polyploidy: From evolution to new plant development. Proc. Intl. Plant Propagators' Soc. 56:604-607.

Sakai, K., Y. Ozaki, M. Hiramatsu, A. Wakana, and H. Okubo. 2006. Intrasubgeneric and interploid cross compatibility in evergreen and deciduous azaleas. J. Fac. Agr. Kyushu Univ. 51:73-81.

Southall, R.M. 1973. A Taxonomic Revision of Kalmia (Ericaceae). North Carolina State Univ., Raleigh, PhD Diss.

Southall, R.M. and J.W. Hardin. 1974. A taxonomic revision of Kalmia (Ericaceae). J. Elisha Mitchell Sci. Soc. 90:1-23.

Weakley, A.S. 2012. Flora of the Mid-Atlantic States. UNC Herbarium, North Carolina Botanical Garden, University of North Carolina, Chapel Hill, NC. 